\title{
Prediction of academic performance based on learning style and critical thinking among medical students
}

\author{
${ }^{1}$ Ardabil University of Medical Sciences, Iran (ORCID: 0000-0001-6065-4397) \\ ${ }^{2}$ Ardabil University of Medical Sciences, Iran (ORCID: 0000-0003-4491-6160) \\ ${ }^{3}$ Ardabil University of Medical Sciences, Iran (ORCID: 0000-0001-9008-8170) \\ ${ }^{4}$ Ardabil University of Medical Sciences, Iran (ORCID: 0000-0003-4612-0895)
}

Aziz Kamran' ${ }^{1}$, Mahdi Naeim², Marzieh Mohammadi ${ }^{3}$ and Nima Masoumi ${ }^{4}$

\begin{abstract}
This study aimed to understand the medical sciences students' critical thinking (CT) and their learning styles and investigate the relationship between academic performance and the both mentioned variables. A descriptive analytical study was conducted on 469 medical sciences students in Ardabil University of Medical Sciences using the Kolb's learning styles and California's CT skills test (Form-B). Cumulative grade point average was considered as academic performance. The data were analyzed with SPSS 18 and using Chi Square test, Independent t-test, one-way ANOVA and Pearson correlation test with a significant level of $p<0.05$. The mean of academic performance was $15.9 \pm 1.7$. The popular learning style among students was assimilative style. Results showed significant relationship between academic performance and learning style. Significant relationship between academic performances of students with the total CT skills was not found, but significant relationship was seen between academic performance and deductive skill only. Learning styles changed in different semesters among medicine and dentistry students from an abstract-reflexive style to a concrete-active one. Using appropriate, active and collaborative teaching methods can help to improve learning and students' academic performance.
\end{abstract}

Keywords: Critical thinking; Academic performance; Teaching and learning; Medical students

Article History: Submitted 6 November 2021; Revised 10 January 2021; Published online 13 February 2021

\section{Introduction}

Students' academic performance is one of the important indicators in the assessment of quality in higher education and all efforts and stretches of educational system are needed to achieve this goal (Ghafoor et al., 2020).The factors affecting academic achievement survey showed that various factors, apart from individual abilities, have an impact on academic performance such as learning styles (Hannan et al., 2020) defined as preferred and unique ways used by individuals to learn and recall information (Jiraporncharoen et al., 2015; Samarakoon et al., 2013).

Address of Corresponding Author

Mahdi Naeim, MSc, Social Determinants of Health Research Center \& Educational Development Center, Ardabil University of Medical Sciences, 56189-85991, Ardabil Province, Iran.

$\triangle 7$ mnaeim64@gmail.com

How to cite: Kamran, A., Naeim, M., Mohammadi, M., \& Masoumi, N. (2022). Prediction of academic performance based on learning style and critical thinking among medical students. Journal of Pedagogical Research, 6(1), 57-66. https://dx.doi.org/10.33902/JPR.2022175483 
Understanding the learning styles of students can provide a tailor-made teaching method in their preferred style and prevent the implementation of a similar teaching method for all students (Lujan \& Dicarlo, 2006). In addition, understanding the learning styles of students helps faculty members to provide different teaching methods and tools to meet the needs of all learners in order to improve their learning (Rassool \& Rawaf, 2007). The poor performance of students is not always due to their inability, but may be due to the inappropriateness of the student's styles of thinking and the teacher's expectations. Research on learning styles and related factors including thinking styles and academic performance originated from studies on the psychological and social dimensions of teaching process and understanding the relationship between thinking and learning styles is in fact one of the major psychological advances but unfortunately limited studies in Iran have investigated this relationship (Ghafoor et al., 2020). Most failures and successes attributed to people's abilities are due to their thinking styles.

The study of the recognition of thinking styles in individuals is important because they function as a bridge between the study of personality and success and this can be useful for predicting the academic achievement of students in the educational environment (Ghafoor et al., 2020). Also, CT is one of the most important goals of higher education, especially in medical education and considered as one of the medical training standards so that the measurement of CT of students is one of the criteria accreditation of a learning institute (Ghazivakili et al., 2014; Hanse, 2012). Physicians are confronted with complex problems in daily health care that require CT to decide on them and CT can increase the decision-making power and clinical competence of the physician in diagnosing and treating patients (Bitran et al., 2012; Pu et al., 2019).

Review of studies shows that despite the importance of CT in the educational system, students' ability to use CT skills has been low. Researchers conducted in Iran mainly indicate the low CT scores of students of different disciplines in comparison with the results of researches conducted in other countries (Amini et al., 2014; Shakurnia \& Aslami, 2017).

In a study conducted by Ja'far Abadi, the total score of CT of students was reported at a low level (Moreira et al., 2020) and in the other two studies in Isfahan and Mazandaran, Athrahi and Sheikh Monsey found that the CT skills in medical students was poor and weak (Kandi Kele et al., 2014; Patel \& Bhatia, 2017).

Although several studies have been conducted around the world on the relationship between academic performance and learning styles and CT, there are limited studies in Iran and existing studies have reported different and contradictory findings. Significant relationship between CT and learning styles of students with their academic performance was not found in the studies conducted by Ziapour and Kianipour (2018), Athari et al. (2013), Shirazi and Heidari (2019), Shakurnia and Aslami (2017) and Tartas et al. (2011). However Ghazivakili (2014), Cecil et al., (2014) and Pu et al., (2019) put forth a significant relationship between CT and student's academic achievement. Furthermore, IsHak et al., (2013) and İlçin et al. (2018) found a relationship between the academic performance and learning styles of the students.

The positive effect of paying attention to learning styles on the growth of students' academic achievement, motivation and teaching methods of teachers has been proven. Therefore, it can be said that determining an effective learning style based on the characteristics of individuals is crucial (Çakıroğlu et al., 2020; Rahmati Najarkolai et al., 2015). Since understanding of learning styles leads to proper planning and guidance in accordance with the prevailing learning style in the teaching-learning process and ultimately can promote the active educational process, one of the goals of this study is to determine the learning styles of the students. Also, considering the contradictions in the results of previous studies and the lack of research in this field, the study of the relationship between CT and learning style with academic achievement is another goal of the present study. 


\section{Method}

\subsection{Research Design}

This study employed a cross-sectional survey design, which are used to gather information about individuals' current attitudes, views, practices or beliefs (Scott \& Morrison, 2006). The present study used a cross-sectional survey design since it investigates the relationship between CT and learning styles with students' academic performance.

\subsection{Participants}

A total of 480 medical sciences students were participated in the study. Eighteen surveys were discarded due to missing item responses. As a result, data obtained from 469 students (response rate was $97.7 \%$ ) were used for the analyses. Students were in the fields of medicine, nursing, midwifery, dentistry, pharmacy and medical emergency. Inclusion criteria were age higher than18-years, official registration in Ardabil University of Medical Sciences [ARUMS] for the 2019-2020 academic year, being an undergraduate student of ARUMS. Exclusion criteria were unwilling to continue participating in the study. The questionnaire was distributed by trained students in the classroom and data was collected by self-reporting.

The age range of the participants was from 20 to 35 with the mean age of $(22.06 \pm 1.8)$. When the participants' characteristics are taken into consideration, it occurred that $58.0 \%$ of participants $(n=272)$ were female, $87.4 \%(n=410)$ were single, $37.7 \%$ of participants' $(n=177)$ were in medicine, $47.3 \%$ of participants $(n=205)$ were in sixth semester, $96.2 \%(n=451)$ were unemployed. The mean of academic performance was 15.9 \pm 1.7 (out of 20) ranged from 11.82 to 18.9 (see Table 1).

Table 1

Demographic variable and student's academic performance

\begin{tabular}{llcc}
\hline Variable & Stages & $N$ & Percentage \\
\hline \multirow{2}{*}{ Gender } & Male & 197 & 42 \\
& Female & 272 & 58 \\
Employment & Unemployment & 451 & 96.2 \\
& Employed & 18 & 3.8 \\
& Medicine & 177 & 37.7 \\
Field of study & Nursing & 155 & 33 \\
& Midwifery & 43 & 9.2 \\
& Medical emergency & 32 & 6.8 \\
& Dentistry & 38 & 8.1 \\
Semester & Pharmacy & 24 & 5.1 \\
& Second \& Third & 87 & 18.6 \\
& Fourth \& fifth & 116 & 24.7 \\
Performance & Sixth \& eight & 205 & 43.7 \\
Age & ten and later & 61 & 13 \\
& & Mean & SD \\
& & 15.90 & 1.72 \\
& & 22.06 & 1.784 \\
\hline
\end{tabular}

\subsection{Data Collection Tool}

The instrument of data collection in the present study was a three-part questionnaire includes demographic section, Kolb's learning styles and California's CT skills test (form B).

The demographic questionnaire included items on employment status, sex, marriage status, age, field of study, academic performance and economic status. The total mean of range of participants' grade points in the past semesters was considered as their academic performance. 
The Kolb's questionnaire includes 12 multiple choice items. The participants respond to questions about how to learn, and the scores of respondents rank from 1 to 4 , in which 4 is most consistent with the learner's learning style 3 to some extent, 2 is poorly consistent and 1 is not compatible with participants' learning styles.

Therefore, this instrument had four total scores for learning styles: the first learning style of concrete experience, the second is reflective observation style, the third is abstract conceptual learning style and the fourth style is active experimentation learning. The highest score determined participatory learning style of the examinee.

The CT skills of students were determined by California CT Skills Test (CCTST) form B in five different areas of CT skills. These skills are evaluation, analysis, inference, inductive reasoning, and deductive reasoning. The CCTST-B Includes 34 multiple choice questions with one correct answer that examines thinking skills from basic analysis of the meaning of sentences to more complex integration. Each item has one correct answer that received one point; so, the total score ranged from 0 to 34, in which higher scores reflect stronger CT skills. Maximum points in the areas of evaluation, analysis, inference are 14, 9, 11, this instrument measure inductive reasoning, and deductive reasoning also, which maximum points in this areas are 16 and 14 respectively. So, in the present study 6 scores reported for each student including a CT total score and 5 subscores for CT skills (Liu et al., 2014; Shin et al., 2006).

\subsection{Data Analysis}

The data were analyzed using the SPSS 18 software. To describe the data, descriptive statistics were used such as mean and standard deviation for continuous variables and frequency for qualitative variables. The normality of data was assessed by the Kolmogorov-Smirnov normality test, and it was shown that our data was normally distributed. Chi Square test, Independent t-test, one way ANOVA and Pearson correlation test were used to determine the relationship between variables at a significant level of $p<.05$.

\section{Results}

The findings of the study have been presented below according to the research questions.

\subsection{Relationship between Demographic Variables and Learning Style}

According to Kolbs' theory, 28.1\% ( $n=132)$ of the participants had the assimilating style (the maximum percentage $), 24.5 \%(n=115)$ had the accommodating style, $24.3 \% \quad(n=114)$ had the divergent learning style and $23.0 \%(n=108)$ had the convergent learning style (the minimum percentage).

Results of the frequency distribution and demographic variables and the academic performance of the students showed that there was not a significant relationship between gender and learning style $(p=.19)$ and also between employment status and learning style $(p=.25)$. Majority of students in field of medicine $(33.9 \%)$ had the divergent learning style; nursing $(35.5 \%)$ had the convergent learning style; midwifery (39.5\%), medical emergency (40.6) and pharmacy (50\%) had the assimilating learning style, and majority of dentistry (31.6\%) had the accommodate learning style (see Table 2).

\subsection{Relationship between Academic Performance and Learning Style}

Results of the one-way analysis of variance (one-way ANOVA) showed significant differences in academic performance among learning style groups $(\mathrm{p}<.001)$. On the other hand, the students with convergent learning style had a better academic performance than those with other learning styles and in the performance of those with the divergent learning style was the weakest (see Table 2). The mean and CI of academic performance of students in four learning styles were presented in Figure 1. 
The relationship between semesters of studying with the learning style was significant at a pvalue of .001 . The majority of students in second and third semesters $(44.8 \%)$ had the divergent learning style, majority of students in fourth/fifth (35.3\%) and sixth/eight (31.7\%) semesters had the assimilating learning style and majority of tenth and subsequent semesters $(42.6 \%)$ had the accommodate learning style. The significant relationship was found between the mean and standard deviation of age among the learning style groups (see Table 2).

Table 2

The relationship between demographic variables and the academic performance with learning styles

\begin{tabular}{|c|c|c|c|c|c|c|}
\hline \multirow[b]{2}{*}{ Variable } & \multirow[b]{2}{*}{ Stages } & \multicolumn{4}{|c|}{ Learning styles } & \multirow[b]{2}{*}{$p$} \\
\hline & & $\begin{array}{c}\text { Assimilate } \\
\mathrm{N}(\%)\end{array}$ & $\begin{array}{c}\text { Divergent } \\
\mathrm{N}(\%)\end{array}$ & $\begin{array}{c}\text { Convergent } \\
\mathrm{N}(\%)\end{array}$ & $\begin{array}{c}\text { Accommodate } \\
\mathrm{N}(\%)\end{array}$ & \\
\hline \multirow{2}{*}{ Gender } & Male & $47(23.9)$ & $46(23.4)$ & $48(24.4)$ & $56(28.4)$ & \multirow{2}{*}{.19} \\
\hline & Female & $85(31.2)$ & $68(25)$ & $60(22.1)$ & $59(21.7)$ & \\
\hline \multirow{2}{*}{ Employment } & Unemployment & $126(27.9)$ & $112(24.8)$ & $101(22.4)$ & $112(24.8)$ & \multirow{5}{*}{.26} \\
\hline & Employed & $6(33.3)$ & $2(11.1)$ & $7(38.9)$ & $3(16.7)$ & \\
\hline \multirow{6}{*}{ Field of study } & Medicine & $31(17.5)$ & $60(33.9)$ & $29(16.4)$ & $57(33.2)$ & \\
\hline & Nursing & $51(32.9)$ & $23(14.8)$ & $55(35.5)$ & $26(16.8)$ & \\
\hline & Midwifery & $17(39.5)$ & $9(20.9)$ & 7 (16.3) & $10(23.3)$ & \\
\hline & $\begin{array}{l}\text { Medical } \\
\text { emergency }\end{array}$ & 13 (40.6) & $10(31.2)$ & $5(15.6)$ & $4(12.5)$ & \multirow[t]{4}{*}{.001} \\
\hline & Dentistry & $8(21.1)$ & $11(28.9)$ & 7 (18.4) & $12(31.6)$ & \\
\hline & Pharmacy & $12(50.0)$ & $1(4.2)$ & $5(20.8)$ & $6(25.0)$ & \\
\hline \multirow{4}{*}{ Semester } & Second\& Third & $19(21.8)$ & $39(44.8)$ & $16(18.4)$ & $13(14.9)$ & \\
\hline & Fourth \& fifth & $41(35.3)$ & $24(20.7)$ & 25 (21.6) & $26(22.4)$ & \multirow{3}{*}{.001} \\
\hline & Sixth \& eight & $65(31.7)$ & $38(18.5)$ & $25.2(25.4)$ & $50(24.4)$ & \\
\hline & Ten and later & $7(11.5)$ & $13(21.3)$ & $15(24.6)$ & $26(42.6)$ & \\
\hline \multicolumn{2}{|c|}{ Performance (Mean $\pm S D)$} & $15.94 \pm 1.6$ & $15.26 \pm 1.7$ & $16.5 \pm 1.4$ & $15.8 \pm 1.7$ & .001 \\
\hline \multicolumn{2}{|l|}{ Age } & $21.74 \pm 1.1$ & $21.66 \pm 1.6$ & $22.31 \pm 2.2$ & $22.5 \pm 1.89$ & .001 \\
\hline
\end{tabular}

The mean and confidence interval of university students' academic performance have been presented in Figure 1 according to the learning styles.

Figure1

The mean and confidence interval of university students' academic performance in four learning styles

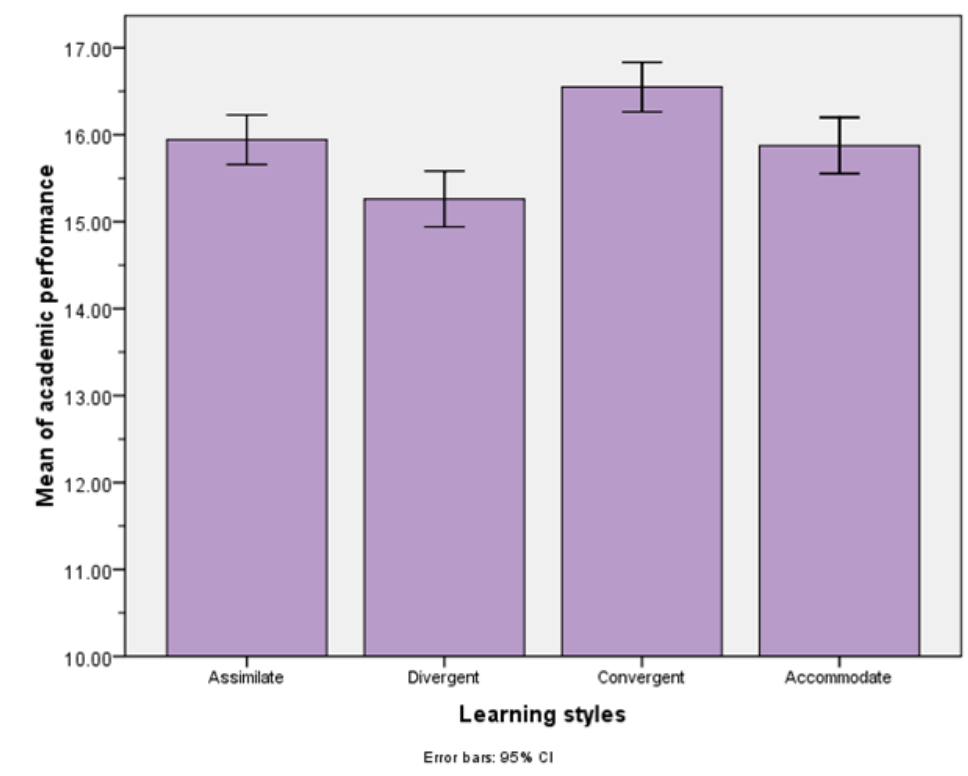




\subsection{Relationship between Demographic Variables and Critical Thinking}

Results showed that there were significant differences in the mean of total score of CT skills among students based on field of study groups, gender and semester groups. Also a significant relationship was found between the fields of study with all of CT skills dimensions. Results showed that male students in analysis dimension and female in the deductive/inductive reasoning dimensions had significantly higher scores $(p<.05)$. In the fields of study group, pharmacy students had significantly higher mean scores in evaluation, analysis, deductive reasoning and medicine students had significantly higher mean scores in inductive reasoning than others $(p<0.05)$.

The Pearson correlation coefficient showed a significant positive relationship between age and CTS total and sub-dimension scores. It means that with the increase of age, the score of CTS was increased. But this relationship was found to be between academic performance and deductive skill only. It means that academic performance of the students had a direct significant relationship with deductive reasoning skill; the more the score, the better the academic performance of the students (see Table 3).

\subsection{Relationship between CTS Scores and Learning Styles}

The mean and standard deviation of CTS scores in the groups of learning style analyzed by ANOVA and results showed significant differences in mean scores of all of the skills among learning styles groups but this significant was not seen in total score of CT (see Table 3).

\section{Discussion}

Learning styles are among the most important variables related to the thinking styles and academic achievement of students. Therefore, studying students' learning styles and thinking is very important (Ghafoor et al., 2020).

Results showed significant relationships between academic performance and learning style which is consistent withllcin et al. (2018), and Shirazi and Heidari (2019), but was inconsistent with Jiraporncharoen et al. (2015) and Nasiri et al. (2016). It seems teaching with active methods such as group discussions and problem based learning can lead to participant-style learning in students and improving academic performance.

Significant relationships between academic performances of students and the total CT skills was not found and significant relationship was found between academic performance and deductive skill only. This finding is consistent with Shirazi and Heidari (2019). The results of Ghazivakili et al. (2014) showed a positive significant relationship between the students' performance and the total score of CT and inferential skill. Moreover, creating a tailored teaching strategy introduced as an important reason for determining learning style. However, learning style is not the influencing factor only on learning situation which can explain this controversies in study results (Ilcin et al., 2018). In addition, the study of Pashler et al. (2008) showed that there is not any evidence that people can learn better when educational system used tailored teaching methods matching with the students' preferred learning styles.

In the present study, the dominant learning styles of nursing and midwifery students and their relationship with academic achievement and thinking styles were studied. The study results showed that the popular learning style among the medicine students was the divergent style, the nursing students had the convergent style, the midwifery and pharmacy students had the assimilating style and the dentistry students had the accommodating style.

The popular learning style among studied students was assimilating style which is consistent with Kolb's theory (Kolb, 2005) and Yenice's (2012) study. People with assimilating style are able to understand the broad information and categorizing them in an accurate and logical method. People with an assimilating learning style are less interested in topics that require work with patients and people. This feature is considered as a disadvantage characteristic for medical students who have this learning style. Also, people with convergent styles that created from the 


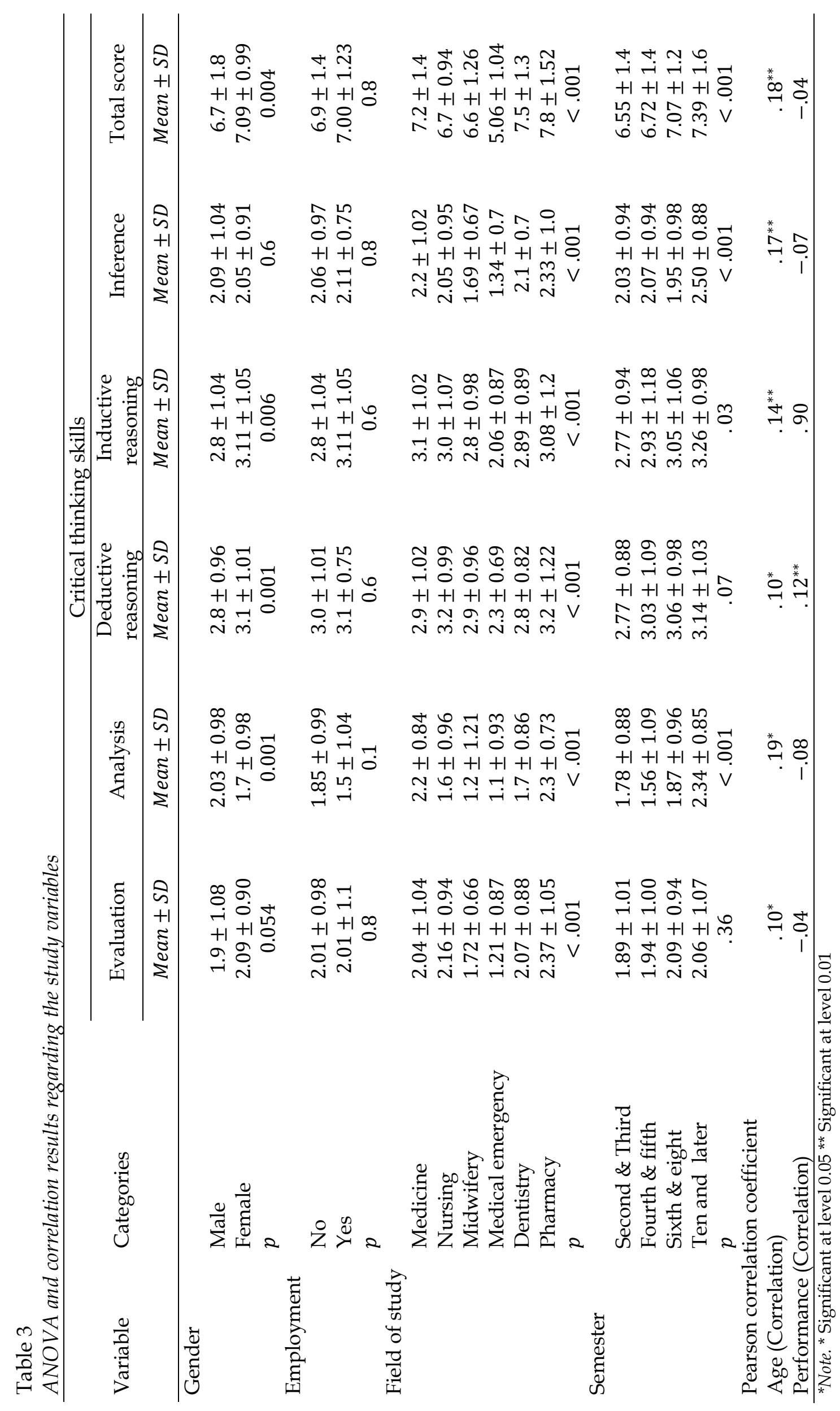


combination of abstract conceptualization and active experimentation, have the ability to solve problems; decide and apply thoughts and theories.

Given the nature and future of medical students, divergent learning styles are more appropriate for them. This style makes them socially active, in particular with patients, in their inventions and attitudes. Such people will be able to make creative, efficient and effective solutions to complex patient issues. It seems that more research is needed on learning styles and the level of interest and satisfaction of individuals in this field. Teachers and designers in medical education system should consider that the variable of learning styles can change according to factors such as learning environment, subjects and teaching styles. The differences in the method of conducted studies, the instruments, the studied participants and cultural diversities may be listed as the main reasons for the controversies found in the study.

Also, the majority of students in second/third semesters (44.8\%) had the divergent learning styles, majority of students in fourth/fifth/sixth/eighth semesters $(35.3 \%)$ had the assimilating learning style and majority of tenth and subsequent semesters $(42.6 \%)$ had the accommodating learning style. This result was consistent with similar studies conducted among medical sciences students (Bitran et al., 2012; Jiraporncharoen et al., 2015) and was inconsistent with the results of some other studies (Ghazivakili et al., 2014; Karimi \& Jamshidi, 2010; Meyari et al., 2009; Samarakoon et al., 2013). This finding can be related to curriculum and teaching methods which change from preclinical to final year in clinical period. It seems that faculty members can have a crucial role in learning of the students through the selection of active and appropriate teaching methods.

In the present study, significant differences in learning styles between male and female students was not found as in the studies of Ojeh et al. (2017), Kircaburun and Danişman (2016), Alkhasawneh et al. (2008), Bitran et al. (2012) and Dobson (2010). However there are other studies (Almigbal, 2015; Dobson, 2009) which have incosistent findings with the current study.

Last of all, learning styles changed in different semesters among medicine and dentistry students from an abstract-reflexive style to a concrete-active one. This change may be due to the nature of the curriculum of the aforementioned disciplines and using appropriate, active and collaborative teaching methods can help them to improve learning and academic performance.

\section{Suggestions and Limitations}

The findings showed that the dominant style in medical students was convergent style. People with a convergent learning style are less interested in topics that require working with people. The medical science profession requires effective interaction and constructive communication with other people, including clients and patients, so it is necessary to strengthen communication skills. It is necessary to emphasize this issue in the revised curriculum of some disciplines as an essential skill and it is suggested that proper planning should be organized for the training and continuous monitoring of students' communication skills. It is possible that students have different learning styles in different courses and teaching styles of teachers. We suggest that this issue should be considered in future studies and the students to be tested in the learning styles over time and in different situations.

There were some limitations to this study. The data collected by self-reported method and study conducted in cross-sectional design which can affect the generalizability of the results of the study. But according to our knowledge, this is the first study in Iranian medical universities that studies and compares the learning styles and CT among students of different majors and semesters with acceptable sample size.

Acknowledgements. The study protocol was approved by the Research Ethics Committee of Ardabil University of Medical Sciences. The study participants remain anonymous and all information that they provide in the questionnaires will be treated as strictly confidential. 


\section{References}

Alkhasawneh, I. M., Mrayyan, M. T., Docherty, C., Alashram, S., \& Yousef, H. Y. (2008). Problem-based learning (PBL): assessing students' learning preferences using VARK. Nurse Education Today, 28(5), 572579. https:// doi.org/10.1016/j.nedt.2007.09.012

Almigbal, T. H. (2015). Relationship between the learning style preferences of medical students and academic achievement. Saudi Med J, 36(3), 349-355. https:/ / doi.org/10.15537/smj.2015.3.10320

Amini, M., Madani, A., \& Askarzaderh, Z. (2014). A study of engineering students' critical thinking skills. Iranian Journal of Engineering Education, 16(63), 39-59.

Athari, Z. S., Sharif, S. M., Nasr, A. R., \& Nematbakhsh, M. (2013). Assessing critical thinking in medical sciences students in two sequential semesters: Does it improve? Journal of Educational Health Promotion, 2, 5. https://doi.org/10.4103/2277-9531.106644

Bitran, M., Zuniga, D., Pedrals, N., Padilla, O., \& Mena, B. (2012). Medical students' change in learning styles during the course of the undergraduate program: from 'thinking and watching' to 'thinking and doing'. Canadian Medical Education Journal, 3(2), e86-97.

Cecil, J., McHale, C., Hart, J., \& Laidlaw, A. (2014). Behaviour and burnout in medical students. Medical Education Online, 19(1), 25209.

Çakıroğlu, Ü., Güler, M., Atabay, M., \& Güler, M. (2020). Connections between learning styles and perceived cognitive load in multimedia learning: An experimental study. Journal of Educational Technology Systems, 48(4), 553-573. https://doi.org/10.1177/0047239519844509

Dobson, J. L. (2009). Learning style preferences and course performance in an undergraduate physiology class. Advanced Physiological Education, 33(4), 308-314. https://doi.org/10.1152/advan.00048.2009

Dobson, J. L. (2010). A comparison between learning style preferences and sex, status, and course performance. Advanced Physiological Education, 34(4), 197-204. https://doi.org/10.1152/advan.00078.2010

Ghafoor, S., Chaudhry, S., \& Khan, J. S. (2020). Marital Status as a Stress Indicator in Postgraduate Dental Students. Journal Of Pakistan Medical Association, 70(1), 158-161.

Ghazivakili, Z., Norouzi Nia, R., Panahi, F., Karimi, M., Gholsorkhi, H., \& Ahmadi, Z. (2014). The role of critical thinking skills and learning styles of university students in their academic performance. Journal of Advanced Medical Education Proffessional, 2(3), 95-102.

Hannan, K. E., Hwang, S. S., \& Bourque, S. L. (2020). Readmissions among NICU graduates: Who, when and why? Seminars in Perinatology, 44(4), 151245.

Hanse, K. (2012). Basic Medical Education, WFME Global Standards for Quality Improvement. University of Copenhagen (Denmark), World Federation for Medical Education.

Ilcin, N., Tomruk, M., Yesilyaprak, S. S., Karadibak, D., \& Savci, S. (2018). The relationship between learning styles and academic performance in TURKISH physiotherapy students. BMC Medical Education, 18(1), 291. https://doi.org/10.1186/s12909-018-1400-2

IsHak, W., Nikravesh, R., Lederer, S., Perry, R., Ogunyemi, D., \& Bernstein, C. (2013). Burnout in medical students: a systematic review. The clinical Teacher, 10(4), 242-245.

Jiraporncharoen, W., Angkurawaranon, C., Chockjamsai, M., Deesomchok, A., \& Euathrongchit, J. (2015). Learning styles and academic achievement among undergraduate medical students in Thailand. Journal of Education and Evaluation in Health Proffession, 12, 38. https:/ / doi.org/10.3352/jeehp.2015.12.38

Kandi Kele, M., Kadivar, M., Zeraati, H., Ahmadnezhad, E., \& Holakoui Naini, K. (2014). Length of stay in NICU admitted infants and its effective factors at children's hospital medical center using survival analysis [Research]. Iranian Journal of Epidemiology, 10(1), 25-32. http://irje.tums.ac.ir/article-1-5204fa.html

Karimi, S., \& Jamshidi, N. (2010). Comparison of learning styles and preferred teaching methods of students in Fasa University of Medical Sciences. Arak Medical University Journal, 12(4), 89-94.

Kircaburun, K. \& Danişman, Ş. (2016). Examining the latitudinal variation of pre-service teachers' learning style profiles. Asian Journal of Instruction, 4(1), 45-58.

Kolb, A. Y. (2005). The Kolb learning style inventory-version 3.12005 technical specifications. Boston, MA: Hay Resource Direct, 200, 72.

Liu, O. L., Frankel, L., \& Roohr, K. C. (2014). Assessing critical thinking in higher education: current state and directions for next-generation assessment. ETS Research Report Series. https://doi.org/10.1002/ets2.12009

Lujan, H., \& Dicarlo, S. (2006). First-year medical students prefer multiple learning styles. Advanced Physiology Education, 30(1), 13-6. https:/ / doi.org/10.1152/advan.00045.2005 
Meyari, A., Sabouri, K. A., Gharib, M., \& Beyglarkhani, M. (2009). Comparison between the learning style of medical freshmen and fifth-year students and its relationship with their educational achievement. Strides Development of Meddical Education, 6(2), 110-118.

Moreira, T., Matos, E., Pacheco, S. R., \& Cunha, M. (2020). The catch-up growth at 2 years of newborns born less than 32 weeks of gestational age. Journal of Pediatric and Neonatal Individualized Medicine (JPNIM), 9(1), e090103.

Nasiri, Z., Gharekhani, S., \& Ghasempour, M. (2016). Relationship between Learning Style and Academic Status of Babol Dental Students. Electron Physician, 8(5), 2340-2345. https://doi.org/10.19082/2345

Ojeh, N., Sobers-Grannum, N., Gaur, U., Udupa, A., \& Majumder, M. A. A. (2017). Learning style preferences: A study of pre-clinical medical students in Barbados. Journal of Advanced Medical Education Proffessional, 5(4), 185-194.

Pashler, H., McDaniel, M., Rohrer, D., \& Bjork, R. (2008). Learning Styles: Concepts and Evidence. Psychological Science Public Interest, 9(3), 105-119. https:/ / doi.org/10.1111/j.1539-6053.2009.01038.x

Patel, P., \& Bhatia, J. (2017). Total parenteral nutrition for the very low birth weight infant. Seminars in Fetal and Neonatal Medicine, 22(1), 2-7. https:/ / doi.org/https://doi.org/10.1016/j.siny.2016.08.002

$\mathrm{Pu}, \mathrm{D} ., \mathrm{Ni}$, J., Song, D., Zhang, W., Wang, Y., Wu, L., Wang, X., \& Wang, Y. (2019). Influence of critical thinking disposition on the learning efficiency of problem-based learning in undergraduate medical students. BMC Medical Education, 19(1), e1. https:/ / doi.org/10.1186/s12909-018-1418-5

Rahmati Najarkolai, A., Beigzadeh, A., Karbasi Motlagh, M., \& Sabzevari, S. (2015). The relationship between learning styles and baseline characteristics of postgraduate students at Kerman University of Medical Sciences during 2013 - 2014. Thrita, 4(2), e27809. https:/ / doi.org/10.5812/thrita.4(2)2015.27809

Rassool, G. H., \& Rawaf, S. (2007). Learning style preferences of undergraduate nursing students. Nursing Standard, 21(32), 35-41. https://doi.org/10.7748/ns2007.04.21.32.35.c4495

Samarakoon, L., Fernando, T., \& Rodrigo, C. (2013). Learning styles and approaches to learning among medical undergraduates and postgraduates. BMC Medical Education, 13, 42. https:/ / doi.org/10.1186/1472-6920-13-42

Scott, D., \& Morrison, M. (2006). Key ideas in educational research. Continuum.

Shakurnia, A., \& Aslami, M. (2017). Critical thinking skills of medical students at Ahvaz Jundishapur University of Medical Sciences. Iranian Journal of Medical Education, 17, 420-427.

Shin, K., Jung, D. Y., Shin, S., \& Kim, M. S. (2006). Critical thinking dispositions and skills of senior nursing students in associate, baccalaureate, and RN-to-BSN programs. Journal of Nursing Education, 45(6), 233237.

Shirazi, F., \& Heidari, S. (2019). The relationship between critical thinking skills and learning styles and academic achievement of nursing students. Journal of Nursing Research, 27(4), e38. https://doi.org/10.1097/jnr.0000000000000307

Tartas, M., Walkiewicz, M., Majkowicz, M., \& Budzinski, W. (2011). Psychological factors determining success in a medical career: a 10-year longitudinal study. Medical teacher, 33(3), e163-e172.

Yenice, N. (2012). A review on learning styles and critically thinking disposition of pre-service science teachers in terms of miscellaneous variables. Asia-Pacific Forum on Science Learning and Teaching, 13(2), a4.

Ziapour, A., \& Kianipour, N. (2018). Health-related quality of life among university students: The role of demographic variables. Journal of Clinical and Diagnostic Research, 12, JC01-JC04. https://doi.org/10.7860/JCDR/2018/29161.11258 